Amar Safdar

\title{
Feasibility of aerosolized colistin in the era of escalating drug-resistant Pseudomonas pneumonia: pressing need for validation clinical trials
}

Received: 17 February 2010

Accepted: 24 March 2010

Published online: 16 April 2010

(C) Copyright jointly held by Springer and ESICM 2010

This editorial refers to the article available at:

doi:10.1007/s00134-010-1879-4.

\section{A. Safdar $(\varpi)$}

Unit 402, Division of Internal Medicine,

Department of Infectious Diseases, Infection Control and Employee Health, The University of Texas M.D. Anderson Cancer Center, 1515 Holcombe Boulevard, Houston, TX 77030, USA

e-mail: asafdar@mdanderson.org

Tel.: +1-713-7920825

Fax: +1-713-7456839

Drug-resistant Pseudomonas aeruginosa, Stenotrophomonas maltophilia, and Acinetobacter species are common pathogens encountered in critically ill patients with bacterial pneumonia [1]. Colistin is cationic lipopeptide, a polymyxin drug that fell out of favor due to concerns over neurotoxic and nephrotoxic side-effects [2]. Alternate route, especially topical applications that directly deliver the drug to terminal respiratory tract, appeared desirable. Two chief concerns regarding topical drug therapy were development of drug resistance and tolerability of inhaled chemicals that may trigger serious irritation and promote potentially deleterious inflammation of respiratory tract. Given that topical administration results in a gradient of antimicrobial drug concentration from central to peripheral airways, there is substantial concern regarding induction of antimicrobial resistance [3]. Whereas case reports and case series have confirmed that resistant organisms can emerge during therapy [4], careful examination during randomized clinical trials has not found emergence of drug-resistant organisms in treated patients to be a particularly significant issue [5].
Recent favorable results in small animals with drugresistant $P$. aeruginosa pneumonia successfully demonstrated role of inhaled colistin in treatment of Gramnegative bacterial pneumonia [6]. Clinical experience for inhaled colistin in patients with Gram-negative pneumonia is based on retrospective, nonrandomized studies including heterogeneous patient populations and confounded by administration of additional antimicrobials in conjunction with inhaled colistin [7, 8]. Despite these limitations, the aforementioned concerns have not been noticed with the use of aerosolized colistin for treatment or prevention of Gram-negative bacterial pneumonia [7$10]$.

Lu et al.'s [11] current study, in nonimmunocompromised large mammals with experimental aerosolized $P$. aeruginosa lung infection treated with either inhaled colistin or intravenous colistin for $24 \mathrm{~h}$, demonstrated that inhaled colistin resulted in relative higher bioavailability of aerosolized drug shown by (area under aerosol concentration-time curve)/(area under plasma concentrationtime curve) $\times$ (intravenous/aerosol colistin dose). This high bioavailability in piglets given inhaled colistin resulted in the expected significantly higher $(39 \%)$ sterilization and reduced bacterial burden in lung tissue compared with animals treated with intravenous colistin. It was also interesting to note that colistin half-life was $1.5 \mathrm{~h}$ longer in animals who received aerosolized drug.

Reduced delivery of drug to area of lung with dense consolidation or large area of necrosis has been a critical concern when using aerosolized medication for pneumonia. In this study, Lu et al. demonstrated that, in areas of severe pneumonia, lower drug concentration occurred with inhaled colistin compared with areas with mild pneumonia; these observations echoed results of prior studies using aminoglycosides [12]. However, despite lung tissue concentrations influenced by severity of lung lesions, inhaled colistin was associated with comparable bacterial clearance in lung segments with mild and severe 
Pseudomonas pneumonia [11]. The reasons for this apparent discrepancy may be hypothetically explained by various ancillary drug transport mechanisms that may facilitate delivery of drug to regions with dense consolidation and necrosis, where direct deposition of aerosolized drug is suboptimal.

The important limitation of this study is lack of efficacy data and how parameters for intravenous colistin may have changed following prolonged intravenous colistin therapy. Another concern is potential bacterial or fungal colonization/infection following antimicrobial selection pressure, resulting in overgrowth of colistinnonsusceptible organisms as seen in lung tissue of piglets treated with inhaled colistin [11]. However, bacterial overgrowth and/or recolonization following aerosolized aminoglycoside had not been a clinical concern in patients with cystic fibrosis receiving aerosolized tobramycin prophylaxis $[3,10]$. Long-term impact of inhaled colistin on bronchial colonization and bacterial overgrowth needs to be further studied. Despite these limitations, this study provides important insight into pharmacokinetics and antimicrobial activity of colistin given by conventional versus aerosolized routes in mammal bearing closer resemblance to humans compared with results obtained in mice.

Clinical experience with aerosolization of antibacterial agents other than aminoglycosides is limited but growing. Taken together, the combination of increasing drug resistance and accumulating data regarding efficacy of inhalation therapy indicates that topical colistin therapy may have a multifaceted role in prevention and treatment of respiratory infection in critically ill patients. Validation of experimental data, and anecdotal and retrospective reports requires prospective randomized multicenter studies in ethnically diverse patients with comparable risk for nonfermentative Gram-negative bacterial pneumonia.

\section{References}

1. Torres A, Ewig S, Lode H, Carlet J, European HAP working group (2009) Defining, treating and preventing hospital acquired pneumonia: European perspective. Intensive Care Med 35:929

2. Wolinsky E, Hines JD (1962) Neurotoxic and nephrotoxic effects of colistin patients with renal disease. N Engl J Med 266:759-762

3. Rubin BK (2008) Aerosolized antibiotics for non-cystic fibrosis bronchiectasis. J Aerosol Med Pulm Drug Deliv 21:71-76

4. Burns JL, Van Dalfsen JM, Shawar RM, Otto KL, Garber RL, Quan JM, Montgomery AB, Albers GM, Ramsey BW, Smith AL (1999) Effect of chronic intermittent administration of inhaled tobramycin on respiratory microbial flora in patients with cystic fibrosis. $\mathbf{J}$ Infect Dis 179:1190-1196

5. Falagas ME, Siempos II, Bliziotis IA, Michalopoulos A (2006) Administration of antibiotics via the respiratory tract for the prevention of ICU-acquired pneumonia: a metaanalysis of comparative trials. Crit Care 10:R123
6. Falagas ME, Rafailidis PI, Ioannidou E, Alexiou VG, Matthaiou DK, Karageorgopoulos DE, Kapaskelis A, Nikita D, Michalopoulos A (2010) Colistin therapy for microbiologically documented multidrug-resistant Gramnegative bacterial infections: a retrospective cohort study of 258 patients. Int J Antimicrob Agents 35:194-199

7. Ghannam DE, Rodriguez GH, Raad II, Safdar A (2009) Inhaled aminoglycosides in cancer patients with ventilator-associated Gram-negative bacterial pneumonia: safety and feasibility in the era of escalating drug resistance. Eur J Clin Microbiol Infect Dis 28:253-259

8. Aoki N, Tateda K, Kikuchi Y, Kimura S, Miyazaki C, Ishii Y, Tanabe Y, Gejyo F, Yamaguchi K (2009) Efficacy of colistin combination therapy in a mouse model of pneumonia caused by multidrug-resistant Pseudomonas aeruginosa. J Antimicrob Chemother 63:534-542
9. Bauldoff GS, Nunley DR, Manzetti JD, Dauber JH, Keenan RJ (1997) Use of aerosolized colistin sodium in cystic fibrosis patients awaiting lung transplantation. Transplantation 64:748-752

10. Safdar A, Shelburne SA, Evans SE, Dickey BF (2009) Inhaled therapeutics for prevention and treatment of pneumonia. Expert Opin Drug Saf 8:435-449

11. Lu Q, Girardi C, Zhang M, Bouhemad B, Louchahi K, Petitjean O, Wallet F, Becquemin $\mathrm{MH}$, Ingeneer GN, Marquette CH, Rouby JJ (2010) Nebulized and intravenous colistin in experimental pneumonia caused by Pseudomonas aeruginosa. Intensive Care Med. doi: 10.1007/s00134-010-1879-4

12. Goldstein I, Wallet F, Nicolas-Robin A, Ferrari F, Marquette CH, Rouby JJ (2002) Lung deposition and efficiency of nebulized amikacin during Escherichia coli pneumonia in ventilated piglets. Am J Respir Crit Care Med 66:1375-1381 